\title{
The consequences of artemisinin resistance in falciparum malaria
}

\author{
Nicholas J White \\ From Challenges in malaria research \\ Basel, Switzerland. 10-12 October 2012
}

Artemisinin resistance in Plasmodium falciparum has emerged in South East Asia. Evidence of resistance in Western Cambodia was documented over six years ago, and last year clear evidence of resistance was reported on the Thailand- Myanmar border. As artemisinin derivatives are the cornerstone of antimalarial treatment both for uncomplicated and severe malaria, their loss will increase morbidity and mortality, and could derail current containment and elimination efforts. In the treatment of severe falciparum malaria artesunate reduced mortality by approximately one third compared with quinine. This resulted from greater parasiticidal activity against circulating ring stage parasites, the very property that is lost in artemisinin-resistance. If we have to return to quinine for the treatment of severe malaria, mortality will rise again. In the treatment of uncomplicated malaria artemisinin resistance results in slower parasite clearance and consequently slower therapeutic responses. Times to recovery are slower, treatment failure rates higher, and transmissibility of the treated infection greater. The reduced antiparasitic effect means that the partner drug now has toeliminate a greater proportion of the infecting parasite biomass, and so there is a greater probability of selecting for partner drug resistance. The future of artemisinin resistance is uncertain; the mechanism underlying resistance has yet to be elucidated. With present levels of resistance artemisinins are still efficacious, albeit much more slowly than before. Whether higher levels of resistance can and will occur is uncertain. Nevertheless, given that previous pandemic spread of antimalarial resistance from South-East Asia killed millions, containing this threat is of the highest global health priority.

Published: 15 October 2012

Mahidol-Oxford Research Unit, Faculty of Tropical Medicine, Mahidol University, Bangkok, Thailand

(C) 2012 White; licensee BioMed Central Ltd. This is an Open Access article distributed under the terms of the Creative Commons Attribution License (http://creativecommons.org/licenses/by/2.0), which permits unrestricted use, distribution, and reproduction in any medium, provided the original work is properly cited.
doi:10.1186/1475-2875-11-S1-036

Cite this article as: White: The consequences of artemisinin resistance in falciparum malaria. Malaria Journal 2012 11(Suppl 1):O36.

Submit your next manuscript to BioMed Central and take full advantage of:

- Convenient online submission

- Thorough peer review

- No space constraints or color figure charges

- Immediate publication on acceptance

- Inclusion in PubMed, CAS, Scopus and Google Scholar

- Research which is freely available for redistribution Submit your manuscript at
www.biomedcentral.com/submit C BioMed Central
C Biomed Central 